

\title{
A theoretical analysis of the relationship between social capital and corporate social responsibility: concepts and definitions ${ }^{1}$
}

\author{
Lorenzo Sacconi ${ }^{\star}$ \\ Giacomo Degli Antoni*
}

\section{Introduction}

Trust, trustworthiness and ethical norms of reciprocity and cooperation have been receiving more and more attention in economic analysis. In particular, two concepts have been widely used in order to study the socio-economic effects of these factors: the concept of social capital (hereafter also SC) and of corporate social responsibility (hereafter also CSR).

After the seminal work by Putnam et al. (1993) that revealed the effect of SC on economic and government performance, many definitions of social capital have been introduced in the literature and have been considered in order to analyse the role of interpersonal relations in affecting economic activity by favouring cooperation ${ }^{2}$.

Different approaches characterize also the notion of CSR. If we look at the stakeholder approach (Freeman 1984, 2000, Freeman and Evan 1990) or at the contractarian approach to CSR (Sacconi 2004; 2006; 2007 a,b), relational aspects, in terms of trust, trustworthiness and spirit of cooperation, may have a key role in

1

We would like to thank Provincia Autonoma di Trento for financial support in the project "Social capital, corporate social responsibility and local economic development".

To be published in Sacchetti S. and Sugden R. (eds), Knowledge in the Development of Economies. Institutional Choices under Globalisation, Edward Elgar, in print.

- Department of Economics, University of Trento and EconomEtica, interuniversity centre of research, Bicocca University, Milano. Email:Llorenzo.sacconi@economia.unitn.it

- EconomEtica, interuniversity centre of research, Bicocca University, Milano. Email: giacomo.degliantoni@unimib.it

${ }^{2}$ It is possible to identify two principal approaches to SC: social capital in terms of generalised trust or civic norms (e.g. Putnam et al. 1993 and Knack and Keefer 1997) and in terms of social networks (e.g. Coleman 1988; Lin 2001; Burt 2002). 
promoting the coordination processes between firm and stakeholders that are essential in order to implement the CSR practices ${ }^{3}$.

Even though SC and CSR seem to be linked by many common elements related to the quality and quantity of social relations between agents, their relationship has not been deeply investigated yet. This paper is aimed at shedding light on some aspects of this relationship, in particular, by investigating the idea of a virtuous circle, between the level of SC and the implementation of CSR practices, that fosters socio-economic development by generating social inclusion and social networks based on trust and trustworthiness.

Following the literature on SC that stresses its multidimensional character (e.g. Paldam 2000), we consider two dimensions of this notion. Starting from the distinction introduced by Uphoff (1999), we take into account a cognitive and a structural idea of SC. The first one essentially refers to the dispositional characters of agents that affect their propensity to behave in different ways. The latter refers to social networks connecting agents.

With regard to the concept of CSR, we adopt a contractarian approach and consider CSR as an extended model of corporate governance, based on the fiduciary duties owed to all the firm's stakeholders (Sacconi 2006; 2007a). Among stakeholders, we distinguish between "strong" and "weak" stakeholders. Both these two categories have made specific investments in the firm. However, strong stakeholders are precious for the firm because they bring in strategic assets. They are, for example, skilled workers or institutional investors. On the contrary, weak stakeholders do not bring strategic assets into the firm and firms have material incentives at defecting in the relationship with them. They are, for example, unskilled workers.

Considering the notions of cognitive and structural SC and a contractarian approach to CSR, we show that:

\footnotetext{
${ }^{3}$ These relational elements related to the networks among firms and stakeholders are indubitably less important with regard to the implementation of CSR practices if one considers other approaches to CSR. This is the case, for example, of the approaches by Friedman (1977) and Jensen (2001). Both these authors do not give much room to the explicit consideration of the stakeholder's interests by the owners of firms (see section 3).
} 
a) the level of cognitive SC plays a key role in inducing the firm to adopt and observe CSR practices that respect all the stakeholders;

b) the decision of adopting formal instruments of CSR contributes to create cognitive SC that is endogenously determined in the model;

c) the level of cognitive SC and the decision of adopting CSR practices creates structural SC in terms of a long term relationship between the firm and the weak and strong stakeholders.

This paper contributes to the literature on social capital, CSR and social networks in two ways. First we take seriously the problem of definition of social capital and analyse the theoretical relationship between two specific forms of SC. We distinguish between a cognitive and a structural dimension of SC and show under which condition cognitive $\mathrm{SC}$ can contribute to the creation of social networks.

Second, the paper examines the complementariness between SC and CSR, showing that they generate a virtuous circle that creates favourable conditions for socioeconomic development. We are not aware of previous studies on this specific topic.

The paper is divided into five sections. In the second and third sections we define respectively the concept of SC and CSR adopted in the paper. In section four we extensively discuss the theoretical connections between the definitions of SC and of CSR. Concluding remarks follow.

\section{A multidimensional approach to social capital}

Starting from the contributions by Coleman $(1988,1990)$ and Putnam et al. (1993), many definitions of SC have been proposed and an agreement on a commonly accepted definition has not been reached. Nevertheless, the multidimensional nature of SC seems to be commonly recognized. We can distinguish at least between two main characterizations of this notion. On one hand, there are definitions that mostly look at the networks that constitute the structure of relations of a single agent or of a community as a whole (Coleman 1988, Lin 2001, Burt 1992, 2002). On the other hand, SC is defined by looking mostly at cultural and mental factors, such as attitude and 
norms (Putnam et al. 1993, Knack and Keefer 1997). Even though these two approaches are linked, there are few analytical studies on the relationship of cause and effect between the definitions of SC in terms of social networks and of attitude and norms. In this perspective one of the attempts is by Uphoff (1999) who distinguishes and analyses the interrelations between two categories of social capital: structural SC and cognitive SC. According to Uphoff's definition "The structural category is associated with various forms of social organization, particularly roles, rules, precedents and procedures as well as a variety of networks that contribute to cooperation, and specifically to mutually beneficial collective action (MBCA), which is the stream of benefits that results from social capital. The cognitive category derives from mental processes and resulting ideas, reinforced by culture and ideology, specifically norms, values, attitudes, and beliefs that contribute cooperative behaviour and MBCA.” (Uphoff 1999, p. 218). In particular, Uphoff stresses that networks "are crucially sustained by expectations (that is, by norms) of reciprocity" and that this reveals the existence of an essential cognitive dimension of networks. Starting from the classification proposed by Uphoff, we define structural SC as cooperative network between agents, and focus on two specific elements of cognitive SC: beliefs and dispositions. Differently from norms and values, beliefs and dispositions have a micro dimension because are referred to single agents. Dispositions can be affected both by macro variables (norms and values shared by the community where agents live) and by micro elements (genetic and psychological factors). Beliefs depend essentially on past experience and on mutual agreement concerning the respect of specific commitments.

Table 1 shows the main features of the two categories of SC according to our definition. Beliefs and dispositions are the constitutive elements of our notion of cognitive SC. Beliefs in the behaviour of others depends on the behaviour they have already had in the past. Moreover, beliefs can be generated or reinforced by ethical commitments that agents take (e.g. subscribing an agreement on a ideal principle). Dispositions principally stem from the norms and values shared in the community where the agents grow up, but they also depend on micro elements such as genetic and psychological factors. Both beliefs and dispositions can promote (or, obviously, reduce) trust and propensity to cooperate. 
Structural social capital is constituted by cooperative linkages between agents. We consider essentially three factors that can promote the creation of cooperative relations: a) beliefs that others will be cooperative, b) disposition to cooperate and c) the existence of effective sanctions that punish the agents that do not cooperate.

Table 1 Categories of Social Capital

\begin{tabular}{|c|c|c|c|}
\hline & \multicolumn{2}{|l|}{ cognitive } & structural \\
\hline $\begin{array}{l}\text { constitutive } \\
\text { elements }\end{array}$ & beliefs & dispositions & cooperative linkages \\
\hline determinants & $\begin{array}{l}\text { ex ante } \\
\text { agreements } \\
\text { ethical } \\
\text { commitments } \\
\text { framing } \\
\text { ex post } \\
\text { learning from } \\
\text { other previous } \\
\text { behaviour } \\
\text { past experience }\end{array}$ & $\begin{array}{l}\text { shared norms } \\
\text { values } \\
\text { genetic and } \\
\text { psychological } \\
\text { factors }\end{array}$ & $\begin{array}{l}\text { beliefs that other will be } \\
\text { cooperative } \\
\text { disposition to cooperate } \\
\text { endogenous social sanctions } \\
\text { against defections }\end{array}$ \\
\hline effects & $\begin{array}{l}\text { trust } \\
\text { cooperation }\end{array}$ & $\begin{array}{l}\text { trust } \\
\text { trustworthiness } \\
\text { cooperation }\end{array}$ & Cooperative relations \\
\hline
\end{tabular}

Source: Authors

After having introduced in the next section the approach to CSR adopted in this paper, we will refer to the distinction between structural and cognitive SC in order to analyze the relationships between SC and CSR. In particular, our aim is to show how social capital and CSR interact generating a virtuous circle that increases the initial endowment of both these factors in a society. 


\section{The approaches to the concept of corporate social responsibility}

There are essentially three different ways to approach the concept of CSR. The first one is to deny or limit substantially the room for the social responsibility of firms. According to Friedman (1977), the only social responsibility of a firm is to make profits respecting the rules, that means without breaking the law. This idea is founded on two arguments. The first one concerns the principle of the maximization of the shareholder's value. A manager must run a firm pursuing the interests of the group of people that he represents because they have given him the control of the firm. The second one comes from the firm belief that the maximization of the shareholder's value implies an optimal use of resources and, consequently, the maximization of total wealth. Jensen (2001) supports the idea that a firm should firstly pursue the shareholder's value maximization. This author stresses that the substitution of this aim with another one - e.g. the maximization of a function that explicitly includes the utility of all the stakeholders could introduce the inability to provide a clear benchmark against which management strategies and company performances can be assessed, being this indeterminacy also the basis for the charge of opening the route to opportunistic behaviour on the part of managers. Moreover, Jensen says that the maximization of shareholder's value is able, in the long run, to solve problems and take into account also the interests of stakeholder that the stakeholder approach to CSR wants to satisfy.

A second way to look at the CSR is to interpret the decision of adopting practices aimed at considering interests of subjects different from shareholders as a kind of philanthropy (Baron 2005).

Finally, according to a more articulated approach to CSR, who runs a firm has to take into account the interests of all the stakeholders. Within this approach it is possible to distinguish between the stakeholder approach and the contractarian approach. The stakeholder approach was introduced by Freeman (1984) who stressed the idea of ethical balance between the interests of the firm and stakeholders in a perspective of strategic management. The contractarian approach to CSR differs from the stakeholder approach principally because it aims at specifying, through a rational agreement (i.e. the social contract), a criterion for defining a balance of the firm's stakeholders interests. 
In this paper we adopt the contractarian approach in order to study the relationship between SC and CSR for two main reasons. First, because the contractarian approach makes it possible to run a firm according to a multi-stakeholder approach by introducing a criterion for defining a balance among the firm's stakeholders. Second, because the social contract underlies the relations between our notions of SC and CSR. In fact, as we will clarify in section 4 , it is the social contract which allows:

a) to activate the agent's beliefs on the firm's behaviour which are a constitutive element of our notion of cognitive SC;

b) the firm to develop a reputation and to induce its stakeholders to start cooperative and fiduciary relations which represent our concept of structural SC.

\subsection{The contractarian approach to CSR}

The contractarian approach to CSR stems from the idea that a firm is an institution that arises in order to solve the incompleteness of contracts and bounded rationality. In a context characterized by incompleteness of contracts and bounded rationality, economic institutions allocate through property rights and hierarchical organizations decision rights to certain parties in any sub-set of the economy. The need for general and abstract ethics principle rises from the risk this discretion may be abused.

Within the theoretical framework of the contractarian approach, we define CSR as a "model of extended corporate governance whereby who runs a firm (entrepreneurs, directors and managers) have responsibilities that range from fulfilment of their fiduciary duties towards the owners to fulfilment of analogous fiduciary duties towards all the firm's stakeholders" (Sacconi 2006).

In order to clarify the introduced definition of CSR two notions require to be expanded: the concept of fiduciary duty and of stakeholders.

The notion of fiduciary duties, refers to situation where a subject has a legitimate interest but is unable to make the relevant decisions in the sense that $\mathrm{s} /$ he does not know what aims to pursue, what alternative to choose, or how to deploy his/her resources in order to satisfy his/her interest. This subject, the trustor, can delegate decisions to a 
trustee giving him the power to choose actions and goals. The trustee may thus count on the resources of trustor and select the appropriate course of action. For a fiduciary relationship to arise, the trustor must have a claim (right) towards the trustee. In other words, the trustee acts and uses the resources made over to him/her in order to achieve results that satisfy (to the best extent possible) the trustor's interests. These claims (i.e. the trustor' s rights) impose fiduciary duties on the agent who is entitled with authority (the trustee), which $\mathrm{s} /$ he is obliged to fulfil ${ }^{4}$.

By the term 'fiduciary duty', therefore, we mean the duty (or responsibility) to exercise authority for the good of those who have granted that authority and are therefore subject to it.

The term stakeholders denotes individuals or groups with a major stake in the running of the firm and who are able to influence it significantly (Freeman and McVea 2002). Different categories of stakeholders can be specified. We introduce a original distinction between strong and weak stakeholders. Both these categories make specific investments in the firm ${ }^{5}$. The key element that allows to distinguish between strong and weak stakeholders concerns the consequences that the break in the relationship with the firm produces both on the stakeholder and on the firm.

a) Strong stakeholder. The difference between the discounted payoff that strong stakeholders and firms get cooperating forever and defecting at the first stage (and not cooperating ever again) is positive. Strong stakeholders bring strategic assets into the firm. They are for example institutional investors or highly skilled workers.

b) Weak stakeholder. Weak stakeholders would like to cooperate forever with the firm, but the discounted payoff that the firm gets cooperating forever with them is lower than the payoff it obtains defecting at the first stage and not cooperating ever again. Weak stakeholders do not bring strategic assets into the firm. They are for example ordinary investors, unskilled workers or unskilled contractors.

The definition of CSR as an extended responsibility towards its stakeholders is rooted in neo-institutional theory (Williamson 1975, 1986; Grossman and Hart 1986; Hart and Moore 1990; Hart 1995; Hansmann 1996). According to this theoretical

\footnotetext{
${ }_{5}^{4}$ On the concept of fiduciary duty see also Flannigan (1989).

${ }^{5}$ Specific investments may significantly increase the total value generated by the firm (net of the costs sustained for that purpose) and are made in relation to a specific firm (and not in any other).
} 
approach, the firm emerges as an institutional form of 'unified transactions governance' aimed at remedying imperfections in the contracts that regulate exchange relations among subjects endowed with diverse assets. The joint use of these assets generates a surplus. Agents must find an agreement on the conditions characterizing their exchange relations. The agreements essentially concern: the reciprocal investment that must be realized to generate the surplus and the way of dividing the surplus. The contracts that have to regulate these agreements can not be complete. They do not include provisos referred to unforeseen events, either because of the costs of drafting them, or because the cognitive limits of the human mind that make it impossible to predict all possible states of the world. It generates the risk of opportunistic behaviour in the case the unforeseen events happen and the renegotiation of the contracts' conditions becomes a necessity. For fear of opportunistic behaviour that the party in a stronger ex post position can have appropriating the entire surplus, thereby expropriating the other stakeholders, agents, that expect to be expropriated, will have no incentive to undertake their investments at the optimal level. This expectation of unfair treatment can generate a loss of efficiency at the social level.

The firm responds to this problem by bringing the various transactions under the control of a hierarchical authority - the authority, that is, of the party which owns the firm and through ownership is entitled to make decisions over the contingencies that were not ex ante contractible ${ }^{6}$. This party is thus safeguarded against opportunism by the other stakeholders and will realize the optimal level of investment. Nevertheless, there is a risk of abuse of authority against the other parties (Sacconi 1999, 2000, 2006). Those wielding authority, in fact, are able to threaten the other stakeholders. The former can exclude the latter from access to physical assets of the firm, or from the benefits of the contract, to the point that those other stakeholders become indifferent between the decision to accept the expropriation and the decision to forego the value of their investments by withdrawing from the relation. Thus the entire surplus, included that part produced by the efforts and investments made by the non controlling stakeholders, will be appropriated by those in a position of authority. Again forward-looking non controlling stakeholders will be deterred to enter in relation with the controlling party.

\footnotetext{
${ }^{6}$ The decision about the party that must have the residual right of control may depend on various factors e.g. a comparative analysis of control's costs of the different stakeholders- see Sacconi 2006 for a deeper explanation.
} 
Many stakeholders among the non controlling ones, will ex ante be discouraged from investing (if they foresee the risk of abuse), while ex post they will resort to conflicting or disloyal behaviour (typically possible when asymmetry of information is inherent in the execution of some subordinate activity) in the belief that they are being subjected to abuse of authority. Therefore, the optimal level of investment could not be achieved and a second best solution arises. All governance solutions based on the allocation of property rights to a single party may approximate social efficiency, but they can never fully achieve it.

The relative (in)efficiency is due to manifest or simply expected unfairness. This is the reason why non optimal level of investment are realized by non controlling stakeholders and it underlines the role that fairness plays in affecting efficiency, at least with regard to the real-life problem of working out an acceptable solution for the governance of transactions.

According to the contractarian approach adopted in this paper, when CSR is viewed as 'extended governance', it can complete the firm as an institution of transactions governance (Sacconi 2000; 2006). The firm's legitimacy deficit is remedied if the residual control right is associated with further fiduciary duties towards the subjects that face the risk of abuse of authority and are deprived of the residual control right. At the same time, this generates an increase in social efficiency because it reduces the disincentives and social costs generated by the abuse of authority. In order to avoid the second best solution due to the risk of abuse of authority, the firm must be ground on a rational agreement (the constitutional contract of the firm) between who runs the firm and the non controlling stakeholders (see Sacconi 2006). The constitutional contract of the firm is the basis not only for the allocation of control over the firm but also to include in this structure other rights - essentially responsibility claims in defence of stakeholders other those protected by the property right. The resulting institutional structure defines the principles of the firm's governance structure consistently with the notion of CSR as a governance model with multiple fiduciary duties.

From this perspective, 'extended governance' should comprise: 
- the residual control rights (ownership) allocated to the stakeholder with the largest investments at risk and with relatively low governance costs (as well as the right to delegate authority to professional directors and management);

- the fiduciary duties of those who effectively run the firm (administrators and managers) towards the owners, given that these have delegated control to them;

- the fiduciary duties of those in a position of authority (the owner or the managers) towards the non-controlling stakeholder. In particular considering the obligation to run the firm so that the non-controlling stakeholders are not deprived of their fair shares of the surplus produced from their specific investments, and that they are not subject to negative externalities.

The constitutional contract of the firm provides that authority should be delegated to the stakeholder most efficient in performing governance functions and defines the fiduciary duties of this part towards the non-controlling stakeholders ${ }^{7}$. In fact, the stakeholders agree to submit to authority, thereby rendering it effective, only if the contract contains the proviso that stipulates that the firm's new governance structure must comply with fiduciary duties towards all the stakeholders (owners and nonowners). Otherwise, the risk of abuse of authority can not be overcome.

The definition of social contract and constitution of the firm stems from the solution of a bargaining cooperative game in which stakeholders must agree on a shared action plan (a joint strategy) which allocates tasks among the members of the team so that the contribution of each of them is efficient (because it produces the maximum surplus net of each stakeholder' s costs) and defines the sharing of the surplus that is generated by the cooperation ${ }^{8}$.

After having specified the contractarian approach to the CSR that we adopt in this paper, after having argued its theoretical foundation in the framework of the neo-

\footnotetext{
${ }^{7}$ Two are the main fiduciary duties towards the non-owners that should be defined in the social contract:

1. to avoid the production of negative external effects on stakeholders not party to transactions, or compensate them so that they remain neutral;

2. to remunerate the stakeholders participating in the firm' $s$ transactions with pay-offs which, taken for granted a fair status quo, must contain a part tied to the firm's economic performance such to approximate fair/efficient shares of the surplus (assuming that this is positive) as envisaged by the first social contract.

${ }^{8}$ With regards to the rational bargaining over the firm constitutions and the related Nash bargaining solution (Nash 1950; Harsanyi 1977) see Sacconi 2006.
} 
institutional theory, and after having introduced the role of the social contract in facing the risk of abuse of authority, we have to analyze the implementation aspects of this notion of CSR. In particular, we are going to investigate if the social contract is also able to induce endogenous incentives and motivations for the firm to adopt the normative model of extended fiduciary duties. Moreover, we will show how this model can be implemented by the firm.

The idea is that the incentives related to the formation of reputation can play a key role in the firm's decision to endorse and respect extended fiduciary duties towards all the stakeholders.. The stakeholders will decide to cooperate with the firm if they trust that it will not abuse of them If stakeholders observe that the firm always respects the social contract, it will increase its reputation and stakeholders will decide to invest at an optimal level into the firm. If they observe an opportunistic behaviour by the firm, its reputation will dramatically diminish.

The problem with regard to the creation of reputation arises because the relations between the firm and its stakeholders are characterized by settings in which information or knowledge about the action of the firm is incomplete or highly asymmetric. Because of incomplete information, the stakeholders can not verify if the firm has actually behaved as a honest cooperative agent by trying to avoid any opportunistic behaviour. Incomplete information essentially eliminates the possibility for the firm to develop a reputation.

In order to avoid the consequences caused by incomplete information on the formation of reputation, the firm must subscribe an explicitly announced standard that sets out general principles, whose contents are such to elicit stakeholder consensus, as well as explicit commitments to compliance with principles and rules which are to be known ex ante by stakeholders. The standard must contain explicit norms with an appropriate structure that must be endorsed by the firm and established in the light of a multi-stakeholder social dialogue, such to induce impartial acceptability.

It is the standard that enables the social mechanism of reputation to function properly by allowing stakeholders to increase their trust in the firm and in its compliance with CSR principles. The standard and the procedures ensuring compliance with it, are announced ex ante; and it is on these - not in relation to particular 
(unforeseen) events or to particular (unobservable) actions or outcomes - that the firm and stakeholders pass homogeneous judgement on ex post compliance with them. The reputation is created if the behaviour of the firm is coherent with the principles declared in the standard ${ }^{9}$. Compliance with CSR voluntary but explicit norms (codes of ethics, management system standards etc.) can solve the incomplete information problem and can allow the firm to develop its reputation and get its share of surplus produced through the cooperation with the stakeholders.

\section{Social capital and corporate social responsibility: a theoretical analysis}

In this section we analyze the relationships between SC and CSR. Our principal aim is to show how SC and CSR interact generating a virtuous circle that increases the initial endowment of both these factors in a society. We identify three main levels of interaction between social capital and CSR.

1. In the first, cognitive SC, understood as dispositions, is an input of CSR. The more individuals who are in contact with firms have disposition to cooperate with agents who respect principles of cooperation, the more firms have incentives to develop a reputation by adopting a CSR standard that declares their compliance with the principles.

2. In the second, the adoption of an explicit CSR standard generates cognitive SC, in terms of beliefs. The commitments to compliance with CSR principles, in terms of fulfilment of fiduciary duties towards all the stakeholders, contributes to determine the beliefs of stakeholders on the cooperative behaviour of firms.

3. Finally, cognitive SC, both dispositions and beliefs, and CSR create the economic incentives that induce the firm to completely fulfil its commitments towards all its stakeholders. It means that firms will decide to cooperate with all its stakeholders creating a cooperative network that would not be created in the absence of cognitive SC and of the adoption of CSR standards.

\footnotetext{
9 This theory of reputation under unforeseen contingencies is fully developed in Sacconi (2000 and 2004d). For a design of a CSR management standard that corresponds to the characters now defined see for example Sacconi DeColle Baldin (2003) and Clarkson Centre for Business Ethics (2002).
} 


\subsection{Conformist preferences and cognitive social capital}

In order to attain this aim, first we have to specify better the concept of cognitive social capital in terms of belief and disposition. We start from the assumption that agents have motives to act that are not purely geared to material advantages (consequences of actions), but which extend beyond the mere material advantage. In particular, we assume that agents have conformist preferences (Grimalda and Sacconi 2002, 2005; Sacconi 2007a) that are defined over states of affairs that are described as sets of interdependent actions characterized in terms of their degree of conformity to a given abstract principle or ideal.

The utility function of agents that have motives to act that depend also on conformist preferences is:

$$
\mathrm{V}_{\mathrm{i}}=\mathrm{U}_{\mathrm{i}}(\sigma)+\lambda_{\mathrm{i}} \mathrm{F}[\mathrm{T}(\sigma)] .
$$

The first term $U_{i}(\sigma)$ is the material utility got by agent $i$ in state $\sigma$. The second term is the ideal utility and reflects the agent's concern with other types of reasons to action, meant in general as the degree of conformity of the social state of affairs $(\sigma)$ - the agent's and the others participants' behaviours - to the normative principle of welfare distribution $\mathrm{T}$.

$\lambda_{\mathrm{i}}$ is an exogenous parameter that represents the disposition to conform to the ideal principle $\mathrm{T}$ given the beliefs in the others' behaviour. The motivation to conform to the principle $T$ for agent $i$ depends on the value of $\lambda_{i}$. The higher $\lambda_{i}$ is, the more the agent $i$ will be disposed to conform to the principle $\mathrm{T}$ if he believes that the others will conform to the principle. $\lambda_{\mathrm{i}}$ represents the endowment of cognitive social capital (in terms of disposition) of agent $i$.

The effects on ideal utility of beliefs (in the degree of conformity to the ideal of other agents) is captured by the function F. Following Grimalda and Sacconi (2002), we 
adopt a particular specification for $\mathrm{F}$ based on an idea of expected mutuality in conforming to the normative prescriptions. If we consider a two-person game, $\mathrm{F}$ can specified by considering two elements ${ }^{10}$ :

1. $f_{i}$ : the index of conditional conformity of player $i$. The value of this index depends on how much the player $\mathrm{i}$ contributes to carry out the ideal $\mathrm{T}$ with his behaviour (i.e by conforming or deviating from the ideal $\mathrm{T}$ ), given what he believes about the other player's choice.

2. $\tilde{f}_{j}$ : the esteem that player $i$ forms about $j$ 's compliance with the ideology. The value of this index depends on how much the other player contributes to carry out the ideal $\mathrm{T}$ with his behaviour (i.e by conforming or deviating from the ideal $\mathrm{T}$ ), given what second player believes (and first player believes that second player believes) that first player will do.

These two indices contribute to determine $\mathrm{F}$ and the utility function becomes:

$$
\mathrm{V}_{\mathrm{i}}\left(\sigma_{\mathrm{i}}, b_{i}^{1}, b_{i}^{2}\right)=\mathrm{U}_{\mathrm{i}}\left(\sigma_{\mathrm{i}}, b_{i}^{1}\right)+\lambda_{\mathrm{i}}\left[1+\bar{f}_{\mathrm{j}}\left(b_{i}^{1}, b_{i}^{2}\right)\right]\left[1+f_{\mathrm{i}}\left(\sigma_{\mathrm{i}}, b_{i}^{1}\right)\right]
$$

Where $b_{i}^{1}$ is the first order belief that player 1 has in the action of player j. $b_{i}^{2}$ is the second order belief about player j's belief in the action adopted by player $\mathrm{i}$.

Both beliefs and dispositions play a key role in determining the (ideal) utility of the stakeholder i:

a) If $\mathrm{i}$ conforms totally to the ideal principle $\mathrm{T}$ and believes that $\mathrm{j}$ will conform totally to the ideal, then the ideal utility of $i$ will assume the maximum value:

$$
\lambda_{i} \times 1 \times 1=\lambda_{i}
$$

b) If $\mathrm{i}$ does not conform completely and believe that also $\mathrm{j}$ will not conform completely, the value of ideal utility will be lower than $\lambda_{\mathrm{i}}$ :

$$
(1-x)(1-y) \lambda_{i}<\lambda_{i}
$$

c) Finally, if the conformity of one of the two agents is zero, the ideal utility got by agent i goes to zero:

\footnotetext{
${ }^{10}$ See Appendix 1 for a formal representation of F.
} 


$$
(1-1)(1-y) \lambda_{i}=0
$$

The belief, in the behaviour of others with regard to their conformity with the ideal principle $\mathrm{T}$, and the disposition, to conform to $\mathrm{T}$ given the belief, determine the value of the ideal utility got by agents that have conformist preferences and are the two elements that constitute our notion of cognitive social capital. The disposition $\lambda$ is generated both by micro and macro factors. First it is related to psychological and genetic factors that affect the disposition of each individual. Second, it is affected by the culture and social norms that characterize the community where the agents live. Belief of agents in the degree of conformity to the principle of others depends on two factors strictly interrelated. First, beliefs can arise in relation to a rational agreement that agents subscribe where they declare the decision to respect and conform to the principle $\mathrm{T}$. Second, they depend on the past behaviour of others (that can confirm or not their actual willingness to conform).

4.2 The CSR principle and the relationship between CSR and cognitive social capital

After having clarified the definition of cognitive SC in terms of dispositions and beliefs, we introduce the notion of CSR and investigate the connection between CSR and cognitive SC with regard to two specific classes of agents: the firm and its stakeholders. The definition of CSR as an extended model of corporate governance, based on the fiduciary duties owed to all the firm's stakeholders enters in this analysis essentially in relation to the principle $\mathrm{T}$. In our analysis $\mathrm{T}$ is the abstract and general principle that the firm must explicitly endorse if it wants to develop a reputation that can induce stakeholders to enter in cooperative relations with it. As we showed in section 3.1, if the firm wants to be trusted by stakeholders, it must subscribe an explicitly announced standard that sets out general principles. This standard allows stakeholders to increase their trust in the firm and in its compliance with the (CSR) principles. A characterisation in contractarian terms of the ideal principle $\mathrm{T}$ is given by the Nash bargaining solution, called also Nash social welfare function $\mathrm{N}$ : 


$$
\mathrm{T}(\sigma)=\mathrm{N}\left(\mathrm{U}_{1}, \ldots, \mathrm{U}_{\mathrm{n}}\right)=\prod_{i=1}^{n}\left(\mathrm{U}_{\mathrm{i}}-\mathrm{d}_{\mathrm{i}}\right)
$$

where $d_{i}$ stands for the reservation utility that agent $i$ can obtain when the bargaining process collapses.

The adoption of the CSR principle by the firm is also interconnected with both the beliefs and the dispositions of the stakeholders who have to decide whether to enter into a cooperative relation with the firm or not.

First, the disposition $\lambda$ of stakeholders may incentive the firm in adopting the CSR standard. In fact, according to our definition of conformist preferences, when $\lambda_{i}$ increases, it increases also the utility of the stakeholder $i$ in cooperating with a firm that conforms to the principle T. Because of that, stakeholders characterized by high levels of $\lambda$ will decide to trust a firm that declares and respects CSR principles sooner than stakeholders with low levels of $\lambda$. It means that a firm, which acts in a context where the stakeholders are endowed by high cognitive SC, will be able to develop a reputation faster and have lower costs than a firm which is related to stakeholders who do not have high endowment of cognitive SC (in terms of $\lambda$ ). Obviously the firm is interested in developing a reputation because it induces stakeholders to invest their resources in the firm at an optimal level with positive effects on the firm's activity.

Second, the adoption of a CSR standard affects the beliefs of the stakeholders. It is only through the explicit declaration of the principle $\mathrm{T}$ that stakeholders can form their beliefs on the type of the firm they are related to. Without the adoption of a CSR standard, because of the incomplete information that characterizes the relations between the firm and its stakeholders (section 3.1), the stakeholders can not form their belief in the conformity of the firm to the principle and, consequently, can not obtain the ideal utility which strictly depends on beliefs.

Dispositions, beliefs and the adoption of a CSR standard can induce stakeholders to cooperate with the firm and to undertake their investments at the optimal level. The stakeholders get a positive material utility in cooperating with the firm until the firm does not abuse them. Moreover, the stakeholders get ideal utility until they observe that the firm conforms to the CSR principle, that is it fulfils its fiduciary duties towards all the stakeholders. If a stakeholder observes an opportunistic behaviour by the firm, its 
reputation will dramatically diminish. A stakeholder loses his ideal utility in cooperating with the firm both if the firm abuses him and if the firm abuses another stakeholder and the loss of the ideal utility depends on the value of $\lambda$.

\subsection{The relationship between CSR, cognitive social capital and structural social capital}

After having discussed the relationship between CSR and cognitive SC, we analyze the role that these two elements have in promoting the creation of structural SC in terms of cooperative relations between the firm and its stakeholders. According to the definitions we introduced in section 3.1, the stakeholders of a firm can be divided into two classes. Strong and weak stakeholders. Looking only at their monetary payoffs, both strong stakeholders and the firm are reciprocally interested in cooperating. On the contrary, the cooperative relation between weak stakeholders and the firm is asymmetric and not sustainable in the long term. The firm has economic incentives in defecting in the relation with weak stakeholders who do not bring strategic assets into the firm.

Obviously, both strong and weak stakeholders are under the risk of abuse of authority. Nonetheless, the strong stakeholders have the possibility to punish the firm which abuses by stopping to cooperate with it ${ }^{11}$. The gain that the firm gets by cooperating with the strong stakeholders reduces the risk of abuse for the latter. Conversely, the weak stakeholders do not have any possibility to avoid the abuse, because the firm is not interested in starting a cooperation process with them and, consequently has no fear of a sanction by the weak stakeholders.

According to our idea, if (strong) stakeholders are endowed by high cognitive SC in terms of dispositions to cooperate with agents who conform to principles of cooperation and they believe that the firm will be cooperative with all the stakeholders, then the firm who contradicts these beliefs by behaving opportunistically with weak stakeholders faces the sanction of the strong ones who may decide to stop cooperating with it. For

11 Moreover, in a previous work, Sacconi (2006) has shown that if stakeholders have conformist preferences, the firm can not apply a mixed strategy or a "refined abuse strategy" (i.e. a strategy which induces an equilibrium in which the firm abuses with the maximum possible probability compatible with maintaining stakeholder indifference between entry and non-entry). 
this reason, in presence of an appropriate structure of dispositions and beliefs, the punishment of strong stakeholders, that consists in stopping their cooperation with the firm, may be a protection against opportunistic behaviour of the firm also for the weak stakeholders.

Let us start from a situation in which the stakeholders of the firm (consumers, suppliers etc.) are characterized by high level of $\lambda$. According to the argument developed in the previous section, this firm will have incentives to adopt the CSR standard. In fact, stakeholders with high level of $\lambda$ will decide to trust a firm that declares and respects CSR principles sooner than stakeholders with low levels of $\lambda$. For this reason, a firm, who acts in a context where stakeholders are endowed by high cognitive SC, will be able to develop a reputation faster and suffer lower costs than a firm which is related to stakeholders who do not have high endowment of cognitive SC (in terms of $\lambda$ ). It is the adoption of the CSR standard which allows the stakeholders to form their beliefs in the respect of cooperative principles by comparing the firm's behaviour with its CSR declaration. The CSR standard, beliefs and dispositions generate a positive ideal utility that the stakeholders get by cooperating with the firm who conforms to the CSR principle.

If the firm decides to stop cooperating with weak stakeholders, because its material payoffs are higher if it defects than if it cooperates with them, then it stops conforming with the ideal CSR principle. If the strong stakeholders of the firm have conformist preferences and they conform to the CSR principle that concerns the fulfilment of the duties towards all the stakeholders, when the firm behaves opportunistically with the weak stakeholders, they lose their ideal utility. If $\lambda$, that is the weight of the ideal utility in the agents' utility function, is high enough, the strong stakeholders may decide to punish the firm which abuses the weak stakeholders. In particular, they may be ready to lose the investment they have made in the firm, i.e. the material utility that they get by cooperating with it, in order to start a new cooperative relation with a firm who conforms to the principle of cooperation. This represents a sanction for the firm that loses the gain that it gets by cooperating with strong stakeholders

The possibility that the strong stakeholders stop their cooperation is a credible threat for the firm because it is connected with endogenous incentives that are determined by 
the role of cognitive SC on stakeholders' ideal utility. The fear of being punished by the strong stakeholders can induce the firm not to abuse the weak stakeholders, thus making cooperative relations sustainable also between the firm and its weak stakeholders.

Starting from a precise definition of cognitive SC, from a contractarian approach to CSR and from the assumption that agents have motives to act that are not purely geared to material advantages (conformist preferences) our theoretical argument leads to a positive relation between cognitive social capital, CSR practices and structural social capital. Cognitive SC and CSR, by reciprocally interacting, generate endogenous incentives for the firm to behave cooperatively with weak stakeholders. In this perspective, they generate the condition for the creation of structural social capital that would not be created otherwise.

Figure 1 summarizes the theoretical relations between cognitive SC, adoption of the CSR standard, creation of reputation and creation of cooperative relations between the firm and its stakeholders.

1 The rational agreement between who runs the firm and the non controlling stakeholders which defines the abstract and general principle $\mathrm{T}$ and the related standard of CSR:

- allow the firm to develop a reputation that can induce stakeholders to enter in cooperative relations with it;

- make possible the creation of the ideal utility (the principle $\mathrm{T}$ has a key role in the utility function of agents with conformist preferences);

- allow the formation of stakeholders' belief in the conformity of the firm to the principle $\mathrm{T}$. 
Figure 1

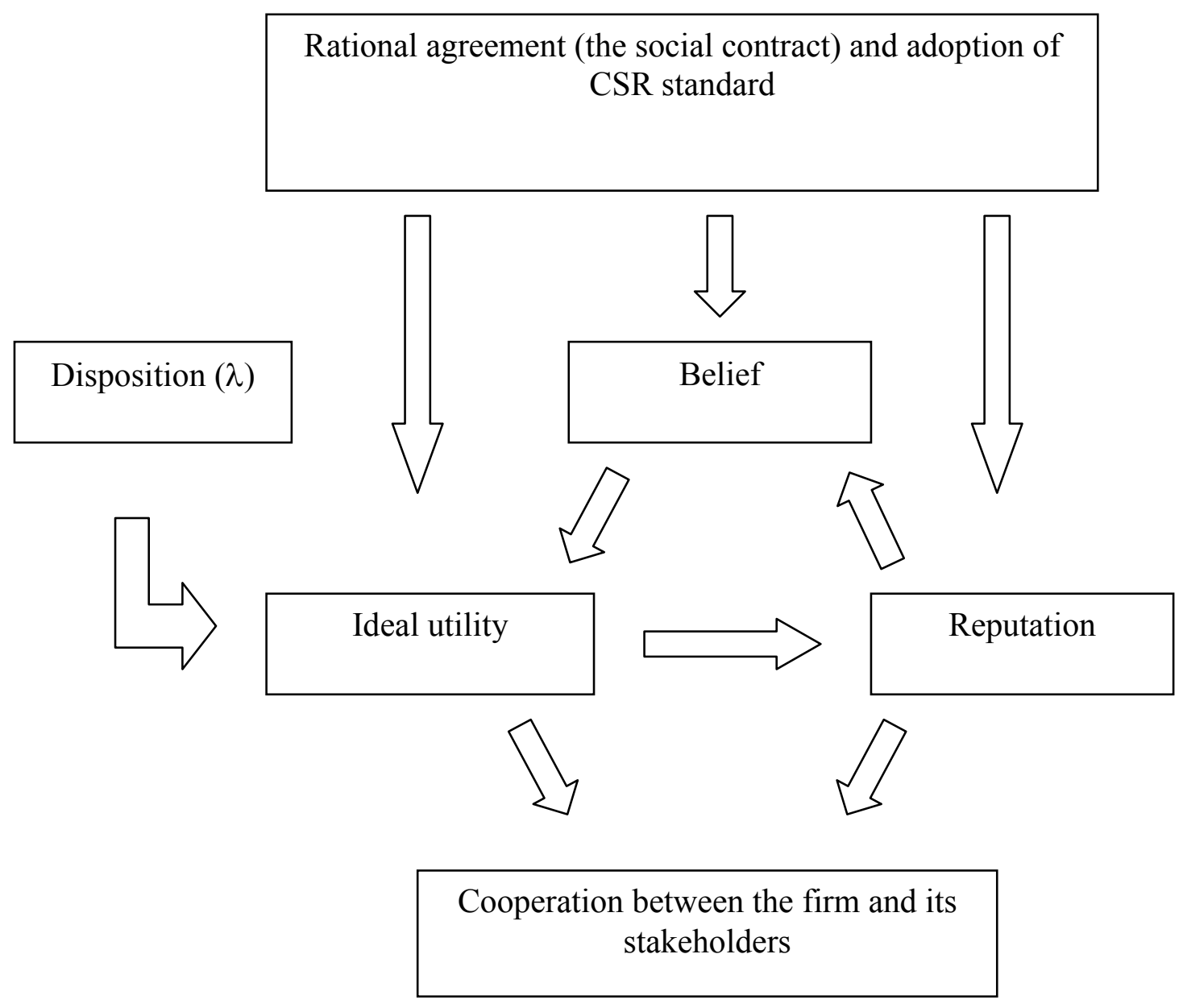

2 Beliefs and dispositions to conform to the CSR ideal principle $\mathrm{T}$ affect the ideal utility which depend on $\lambda$ (when $\lambda_{\mathrm{i}}$ increases, it increases also the utility of the stakeholder $\mathrm{i}$ in cooperating with a firm that conforms to the principle $\mathrm{T}$ ) and on the belief on the others' behaviour with respect to the conformity with the principle $\mathrm{T}$.

3 The ideal utility reduces the cost of developing a reputation. Stakeholders who obtain ideal utility by cooperating with a firm which respects the CSR principle $\mathrm{T}$ will trust the firm sooner than stakeholders who do not obtain ideal utility.

4 A good reputation contributes to increase belief that the firm will respect the CSR principle. Stakeholders with conformist preferences who notice that the firm has a 
good reputation (because it respects its commitments) will reinforce their belief in the cooperative character of the firm.

5 Ideal utility and reputation induce stakeholders to enter into a cooperative relation with the firm. In particular, the ideal utility obtained by strong stakeholders in cooperating with a firm which confirms to the principle $\mathrm{T}$ could induce the firm to respect all the stakeholders. In fact, if the firm stops to cooperate with weak stakeholders, the strong stakeholders lose their ideal utility in cooperating with it If $\lambda$ is high enough, the strong stakeholders may decide to punish the firm which abuses the weak stakeholders by stopping their cooperation with it. This possibility is a credible threat for the firm because it is connected with endogenous incentives related to the effect of cognitive SC on stakeholders' ideal utility. The fear of being punished by the strong stakeholders can induce the firm not to abuse the weak stakeholders, thus making cooperative relations sustainable also between the firm and its weak stakeholders and generating structural SC.

\section{Conclusion}

The aim of this paper was to investigate the relationship between social capital and CSR. Our principal point has been to highlight the importance of cognitive SC, understood as dispositions and beliefs, and CSR principles in generating networks of cooperative relations between the firm and its stakeholders. In order to obtain this goal, we have introduced a definition of CSR coherent with a contractarian approach and two different notions of SC, the cognitive and the structural social capital. Cognitive SC has been defined as dispositions to conform with ethical principles of cooperation and as beliefs in other conformity to the same principles. With regard to the CSR notion, it has been defined as a model of extended corporate governance whereby who runs a firm have responsibilities that range from fulfilment of their fiduciary duties towards the owners to fulfilment of analogous fiduciary duties towards all the firm's stakeholders. We have also introduced a distinction between strong and weak stakeholders. The former bring in the firm strategic assets, the latter invest in the firm but without bringing 
in strategic assets. The firm is interested in cooperating in the long term with strong stakeholders and it is not interested in doing the same with weak stakeholders.

According to our theoretical argument, the disposition of stakeholders to conform with agents who share ethical principles of cooperation represents a incentive for the firms to adopt CSR standards. Stakeholders who are characterized by this kind of disposition will trust a firm who respects ethical principles of cooperation sooner than stakeholders who are not. For this reason, to declare (and to observe) CSR principles is more convenient for a firm who acts in a context characterized by high level of cognitive social capital (in terms of dispositions) than for a firm who is connected with stakeholders who are not endowed by cognitive social capital.

In order to arise trust in stakeholders, because of the incompleteness of contracts and bounded rationality, the firm has to explicitly declare the principles (in terms of fulfilling of the fiduciary duties towards all the stakeholders) that will characterize its behaviour. By comparing the statements, formulated in the CSR standard, and its behaviour, the stakeholders can check if the firm actually respects its duties. The CSR standard is essential in order to allow stakeholders to form their beliefs in the conformity of the firm to the ethical principles of cooperation and to decide if they may trust the firm.

After dispositions have fostered the diffusion of CSR principles and the CSR standard has activated the beliefs, we will observe that stakeholders (both weak and strong stakeholders) start a cooperative relationship with the firm and start to undertake investment at an optimal level in the firm.

According to our idea of conformist preferences, stakeholders characterized by cognitive SC do not get only an economic payoff by cooperating with a firm who conforms with ethical principles of cooperation. They also get an ideal utility that originates from the fact of cooperating with a firm who respects the principles with which they want to conform.

If the firm behaves opportunistically with one or more stakeholders the ideal utility goes to zero for all the stakeholders, because they observe that the firm stops conforming to the ethical principles of cooperation. If the loss of the ideal utility is high enough, the stakeholders may decide to interrupt their cooperation with the firm (and maybe to start a new relation with another firm who respects the principles). This 
possibility does not worry the firm when it concerns only the weak stakeholders. On the contrary, the interruption of the cooperation may generate a economic loss for the firm if it is decided by strong stakeholders.

On the basis of these premises, the reasoning developed in section 4.3 has shown that the cognitive SC of strong stakeholders, associated with the adoption of CSR practices by the firm, may avoid opportunistic behaviour of the firm against weak stakeholders, even though, in each single relationship with weak stakeholders, the firm would have economic incentive to defect. Essentially, the possibility that strong stakeholders decide not to cooperate with the firm if it defects with weak stakeholders is a reliable threat for the firm that may decide (it depends on the payoff structure) to cooperate with weak stakeholders in order to avoid sanctions from strong stakeholders.

In conclusion, our analysis identifies the conditions for a virtuous circle between cognitive SC, CSR and structural SC. In particular, dispositions, beliefs and CSR practices make sustainable cooperative relations between the firm and its weak stakeholders that would not be sustainable otherwise. This is a socially desirable result because: 1) all the stakeholders undertake investment at an optimal level in the firm; 2) the cooperation between the firm and all its stakeholders is successful and generates an higher total output than the total output that would be generated by opportunistic behaviour.

\section{Appendix 1}

In this appendix we focus on the function $\mathrm{F}$ which is a function, shared by all the agents, of the social normative criterion $\mathrm{T}$.

Following Grimalda and Sacconi (2002), we adopt a particular specification for $\mathrm{F}$ based on an idea of expected mutuality in conforming to the normative prescriptions. Grimalda and Sacconi (2002) restrict the attention to a two-person game and define two indices that contribute to determine F: 
1. $f_{\mathrm{i}}$ : the index of conditional conformity of player $\mathrm{i}$ (or degree of deviation from pure conditional conformity with T):

$f_{\mathrm{i}}\left(\sigma_{\mathrm{i}}, b_{i}^{1}\right)=\frac{T\left(\sigma_{i}, b_{i}^{1}\right)-T^{M A X}\left(b_{i}^{1}\right)}{T^{M A X}\left(b_{i}^{1}\right)-T^{M I N}\left(b_{i}^{1}\right)}$

Where $T^{M A X}\left(b_{i}^{1}\right)$ and $T^{M I N}\left(b_{i}^{1}\right)$ are respectively the maximum and minimum value that the welfare distribution function, representing the normative principle or ideology, can assume, depending on $i$ 's action, given $i$ 's first order belief , $b_{i}^{1}$, over the action that $j$ is going to perform. $T\left(\sigma_{i}, b_{i}^{1}\right)$ is the actual level of $\mathrm{T}$ when player $\mathrm{i}$ implements strategy $\sigma_{\mathrm{i}}$ given what he expects from player $j$.

$f_{\mathrm{i}}$ varies from 0 (no deviation at all from the principle $\mathrm{T}$ ) to -1 (maximal deviation).

2. $\bar{f}_{\mathrm{j}}$ is the esteem that player $i$ forms about $j$ 's compliance with the ideology.

$$
\bar{f}_{\mathrm{j}}\left(b_{i}^{1}, b_{i}^{2}\right)=\frac{T\left(b_{i}^{1}, b_{i}^{2}\right)-T^{M A X}\left(b_{i}^{2}\right)}{T^{M A X}\left(b_{i}^{1}\right)-T^{M I N}\left(b_{i}^{2}\right)}
$$

$b_{i}^{1}$ is the first order belief that player 1 has in the action of player $\mathrm{j} . b_{i}^{2}$ is the second order belief about player j's belief in the action adopted by player i. $T^{\text {MAX }}\left(b_{i}^{1}\right)$ and $T^{M I N}\left(b_{i}^{2}\right)$ are the value that the welfare function takes when player $j$ respectively maximises or minimises it, given the second order belief of player $i$. In other words, those functions indicate the maximum and minimum value that player $j$ can attribute to the welfare function, given the belief he has about $i$ 's action as perceived by $i$ himself. $\mathrm{T}\left(b_{i}^{1}, b_{i}^{2}\right)$ is the actual value that $i$ expects the welfare function to take according to his beliefs. $\bar{f}_{\mathrm{j}}$ varies between 0 and -1 that respectively indicates the maximum and minimum degree of conformity by player $j$ to the ideology as embodied in the welfare function $T$.

Implementing these definitions, the utility function of agents can be written:

$\mathrm{V}_{\mathrm{i}}\left(\sigma_{\mathrm{i}}, b_{i}^{1}, b_{i}^{2}\right)=\mathrm{U}_{\mathrm{i}}\left(\sigma_{\mathrm{i}}, b_{i}^{1}\right)+\lambda_{\mathrm{i}}\left[1+\bar{f}_{\mathrm{j}}\left(b_{i}^{1}, b_{i}^{2}\right)\right]\left[1+f_{\mathrm{i}}\left(\sigma_{\mathrm{i}}, b_{i}^{1}\right)\right]$

\section{References}


Baron, D.P. (2005),"Corporate Social Responsibility and Social Entrepreneurship", Research Paper Series n¹916, Stanford, Graduate School of Business.

Burt, R. (1992), Structural Holes, Cambridge, Mass.: Harvard University Press.

Burt, R. (2002), "The Social Capital of Structural Holes”, in M.F. Guillen, R. Collins, P. England, and M. Meyer (eds), The New Economic Sociology, New York, Russell Sage Foundation.

Clarkson Centre for Business Ethics (2002),'Principles of Stakeholder Management", Business Ethics Quarterly, 12 (2), 257-264

Coleman, J.S. (1988),"Social Capital in the Creation of Human Capital", American Journal of Sociology, 94, 95-120.

Coleman, J.S. (1990), Foundations of Social Theory, Cambridge, Harvard University Press.

Flannigan, R. (1989),“The Fiduciary Obligation”, Oxford Journal of Legal Studies, 9, 285-294.

Freeman, E. (1984),Strategic management, A Stakeholder Approach, Pitman, Boston.

Freeman, E. (2000),"Business Ethics at the Millennium", in Business Ethics Quarterly, $10,1,169-180$.

Freeman, T. and W.M. Evan (1990),"Corporate Governance: A Stakeholder Interpretation", The Journal of Behavioural Economics, 19, n. 4, pp. 337-359.

Freeman, R.E. and J. McVea (2002),"A stakeholder approach to strategic management", Working paper n.01-02, Darden Graduate School of Business Administration.

Friedman M. (1977),'The social responsibility of Business is to make profits", in Steiner G.A. and J.F. Steiner, Issues in Business and society, New York, Random House.

Grimalda, G. and L. Sacconi (2002),"'The constitution of the nonprofit enterprise: ideals, conformism and reciprocity", Liuc Papers $n$. 115, Serie Etica, Diritto ed Economia. 
Grimalda, G. and Sacconi L. (2005), The Constitution of the Not-For Profit Organization: Reciprocal Conformity, Constitutional Political Economy, 16 (3), 249276.

Grossman, S. and O. Hart (1986), "The Costs and Benefit of Ownership: A Theory of Vertical and Lateral Integration”, Journal of Political Economy, 94, 691-719.

Hansmann, H. (1996), The ownership of enterprise, Cambridge, Mass.: Harvard University Press.

Harsanyi, J.C. (1977), Rational Behaviour and Bargaining Equilibriumin Games and Social Situations, Cambridge, Cambridge University Press.

Hart, O. (1995), Firms, Contract and Financial Structure, Oxford, Clarendon Press.

Hart, O. and J. Moore (1990),"Property Rights and the Nature of the Firm", Journal of Political Economy, 98, 1119-1158.

Jensen, M.C. (2001),"Value Maximization, Stakeholder Theory, and the Corporate Objective Function”, Journal of Applied Corporate Finance, 14 (3), 8-21.

Knack, S. and P. Keefer (1997),'Does Social capital have an economic payoff? A cross country investigation", The Quarterly Journal of Economics, CXII, 1251-1287.

Lin, N. (2001), Social Capital, Cambridge, Cambridge University Press.

Nash, J. (1950),“The Bargaining Problem”, Econometrica, 18, 155-162.

Paldam, M. (2000),"Social Capital: one or many? Definition and Measurament", Journal of Economic Surveys, 14 (5), 629-653.

Putnam, R., R. Leonardi and R. Nanetti (1993). Making Democracy Work: Civic Traditions in Modern Italy, Princeton University Press.

Sacconi, L. (1999), “Codes of ethics as contractarian constraint on abuse of authority: a perspective from the theory of the firm”, Journal of Business Ethics, 21, 189-202. 
Sacconi, L. (2000), The social contract of the firm, Economics, Ethics and Organisations, Berlin, Springer Verlag.

Sacconi, L. (2004),'Incomplete Contracts and Corporate Ethics: A Game Theoretical Model under Fuzzy Information", in F. Cafaggi, A. Nicita and U. Pagano (eds), Legal Orderings and economic institutions, London, Routledge.

Sacconi, L. (2006),"A Social Contract Account For CSR as Extended Model of Corporate Governance (I): Rational Bargaining and Justification", Journal of Business Ethics, Special Issue on Social Contract Theories in Business Ethics, 259-281.

Sacconi, L. (2007a),"A Social Contract Account for CSR as Extended Model of Corporate Governance (II): Compliance, Reputation and Reciprocity", Journal of Business Ethics, 75 (1), 77-96.

Sacconi, L. (2007b),"CSR as a model of extended corporate governance, an explanation based on the economic theories of social contract, reputation and reciprocal conformism", in F. Cafaggi, Profiles of self-regulation, Kluwer Academic Press; $\begin{array}{llll}\text { Electronic } & \text { publication } & \text { SSRN } & \text { (March }\end{array}$ http://papers.ssrn.com/sol3/papers.cfm?abstract $\mathrm{id}=514522$.

Sacconi, L., S. DeColle and E. Baldin (2003),'The Q-RES Project: the Quality of Social and Ethical Responsibility of Corporations", in J. Wieland (ed.),Standards and Audits for Ethics Management Systems, The European Perspective, Berlin, Springer Verlag., pp.60-117.

Uphoff, N. (1999),"Understanding Social Capital: Learning from the Analysis and Experience of Partecipation", in P. Dasgupta and I. Serageldin (eds),Social Capital : A Multifaceted Perspective, Washington, The World Bank.

Williamson O. (1975), Market and Hierarchies, New York, The Free Press.

Williamson O.(1986), The Economic Institution of Capitalism, New York, The Free Press. 